\title{
Determination of the Glycosylation Site of Flavonoid Monoglucosides by Metal Complexation and Tandem Mass Spectrometry
}

\author{
Barry D. Davis and Jennifer S. Brodbelt \\ Department of Chemistry and Biochemistry, The University of Texas at Austin, Austin, Texas, USA
}

\begin{abstract}
Metal complexation and tandem mass spectrometry were used to differentiate C- and O-bonded flavonoid monoglucoside isomers. Electrospray ionization of solutions containing a flavonoid glycoside and a metal salt led to the generation of the key [M(II) (L) (L-H)] ${ }^{+}$ complexes, where $\mathrm{M}$ is the metal ion and $\mathrm{L}$ is the flavonoid glycoside. Thirteen flavonoid monoglucosides were examined in combination with $\mathrm{Ca}(\mathrm{II}), \mathrm{Mg}(\mathrm{II}), \mathrm{Co}(\mathrm{II}), \mathrm{Ni}(\mathrm{II})$, and $\mathrm{Cu}(\mathrm{II})$. Collisional activated dissociation (CAD) of the $[\mathrm{M}(\mathrm{II})(\mathrm{L})(\mathrm{L}-\mathrm{H})]^{+}$complexes resulted in diagnostic mass spectra, in contrast to the CAD mass spectra of the protonated, deprotonated, and sodium-cationized flavonoid glucosides. Five common sites of glycosylation could be predicted based on the fragmentation patterns of the flavonoid glucoside/magnesium complexes, while flavonoid glucoside/calcium complexes also were effective for location of the glycosylation site when $\mathrm{MS}^{3}$ was employed. Cobalt, nickel and copper complexation had only limited success in this application. The metal complexation methods were also applied for characterization of a flavonoid rhamnoside, and the dissociation pathways of the metal complexes indicate that flavonoid rhamnosides have distinctive dissociation features from flavonoid glucosides. (J Am Soc Mass Spectrom 2004, 15, 1287-1299) (C) 2004 American Society for Mass Spectrometry
\end{abstract}

$\mathrm{F}$ lavonoids comprise a class of phytochemicals sharing a common 15-carbon polyphenolic skeleton. Their ubiquitous presence in plants makes them an integral part of the human diet. Flavonoids have gained prominence with reports that their consumption may confer health benefits as antioxidants, anticancer agents, immune system stimulants, and antiinflammatories [1-3]. Thousands of flavonoids have been discovered [4], differing by the location of hydroxyl and methoxyl groups, and by the placement, number, and identity of saccharide moieties. Other modifications, such as sulfonation and glucuronidation, can occur as a result of metabolism. The high degree of variety in flavonoid structure makes accurate identification a critical step in the confirmation of their chemopreventive properties.

Much research has been devoted to structural elucidation of flavonoids by mass spectrometry $[5,6]$. Several groups have reported characterization of flavonoids by electron ionization (EI) [6-10] or fast atom bombardment (FAB) mass spectrometry [7, 11-19]. More recently, electrospray ionization (ESI) [19-29],

Published online July 28, 2004

Address reprint requests to Dr. J. S. Brodbelt, Department of Chemistry and Biochemistry, The University of Texas at Austin, 1 University Station A5300, Austin, TX 78712-0165, USA. E-mail: jbrodbelt@mail.utexas.edu atmospheric pressure chemical ionization (APCI) [27$31]$, and matrix-assisted laser desorption ionization (MALDI) [32,33] have been used to analyze flavonoids, typically in conjunction with tandem mass spectrometry (MS/MS) or high-performance liquid chromatography (HPLC). Despite these inroads, mass spectrometric analysis has not yet reached the point where de novo identification of flavonoids is possible. Analysis of flavonoids in plant extracts [34-40], foodstuffs [41-46], and human biological fluids [47-49] have been reported, but the identity of flavonoids in these complex matrices generally must be confirmed by comparison with commercial standards. Otherwise only tentative identifications can be made, particularly in terms of saccharide location and identity, unless supplementary analytical methods, such as UV, FTIR, or NMR spectroscopy, are employed. Some researchers have tried derivatization to enable unambiguous identification by mass spectrometry $[11,19,34]$, but this is a difficult and time-consuming approach.

Some significant progress has been made towards systematic structural characterization of flavonoids by mass spectrometry. The fragmentation pathways of flavonoid aglycons obtained by tandem mass spectrometry have been well-documented [13, 22, 23, 27, 50]. In addition, commonly encountered diglycosyl flavonoids can often be distinguished by their fragmentation path- 
ways [14, 18, 20, 51, 52]. For less common flavonoid glycosides, methods have recently been proposed for determining the saccharide identity [19], as well as the linkage order [14]. Furthermore, distinctive patterns have been reported for methoxylated flavonoids [15, 25] and for chlorinated and nitrated isoflavonoids [26]. Hydrogen/deuterium exchange has also been explored as a method for flavonoid isomer differentiation [53].

The problem of determining the glycosylation site of monoglycosyl flavonoids has also been addressed. The general fragmentation differences between flavonoid glycosides bonded through carbon versus oxygen atoms have been established [16], along with differentiation of 6-C-glycosyl and 8-C-glycosyl flavonoids [16, 17, $29,38,54]$. However, to our knowledge no one has proposed a robust universal mass spectrometric method for determining five of the most common glycosylation positions encountered for the monoglucosyl flavonoids: attachment through oxygen at position $3,4^{\prime}$, or 7 ; or through carbon at position 6 or 8 . We report a successful method for achieving this latter goal based on metal complexation and tandem mass spectrometry.

A number of groups have studied metal complexes by mass spectrometry and found that the fragmentation pathways of analytes can be significantly altered, allowing new opportunities for structural determination [5571]. The Brodbelt group has shown that metal complexation combined with the use of a neutral auxiliary ligand dramatically increases sensitivity for detection of flavonoids while also providing a richer array of fragments to aid in isomer differentiation [50-52, 72]. Although this approach proved beneficial for differentiating diglycosyl flavonoids [51], the same approach for monoglycosyl flavonoids was less successful: several different complexation modes were required to fully differentiate isomers [52]. In this work, by dispensing with auxiliary ligands we developed a new metal complexation strategy for resolving many isomeric monoglucosyl flavonoids. The resulting fragmentation pathways were remarkably consistent based on the position of the glucose moiety, providing a simple means for determining the glycosylation site of flavonoid glucosides. Thirteen flavonoid glucosides are included in this study (Figure 1), involving glycosylation at five different positions on the flavonoid skeleton. The flavone, flavonol, and flavanone classes are represented by the sample compounds. One flavonoid rhamnoside is also included to explore the effects of saccharide identity on fragmentation.

\section{Experimental}

All experiments were performed with an LCQ Duo quadrupole ion trap mass spectrometer (ThermoFinnigan, San Jose, CA) with an electrospray ionization (ESI) source. The ESI flow rate was $5 \mu \mathrm{L} / \mathrm{min}$, and the ion injection time was typically $10 \mathrm{msec}$ for full scans and $50 \mathrm{msec}$ for $\mathrm{MS}^{2}$ and $\mathrm{MS}^{3}$ experiments. 100 microscans were averaged for each spectrum. The mass spectrometer was tuned for maximum intensity of the ion of interest. Protonated flavonoid glycosides, metal complexes, and sodium adducts were analyzed in the positive ion mode; and deprotonated flavonoid glycosides were analyzed in the negative ion mode. The following electrospray conditions were used in analyzing the metal complexes: Needle voltage $+5 \mathrm{kV}$, sheath gas flow rate 5 arbitrary units, no auxiliary gas, heated capillary temperature $200{ }^{\circ} \mathrm{C}$, capillary voltage $20 \mathrm{~V}$, and tube lens offset $20 \mathrm{~V}$.

Quercetin-3-O-glucoside, naringenin-7-O-glucoside, spiraeoside, and homoorientin were purchased from Extrasynthèse (Genay, France). Kaempferol-3-O-glucoside, isorhamnetin-3-O-glucoside, luteolin-4'-O-glucoside, apigenin-7-O-glucoside, luteolin-7-O-glucoside, vitexin, isovitexin, orientin, and quercitrin were purchased from Indofine (Somerville, NJ). Quercetin-7-Oglucoside was purchased from Apin Chemicals (Abingdon, UK). Certified ACS Spectranalyzed methanol was purchased from Fisher Scientific (Pittsburgh, PA). $\mathrm{CoBr}_{2}, \mathrm{NiBr}_{2}, \mathrm{CuBr}_{2}$, and $\mathrm{MgCl}_{2}$ were purchased from Aldrich (Milwaukee, WI). $\mathrm{CaBr}_{2}$ was purchased from Matheson, Coleman and Bell (Cincinnati, OH). All materials were used without further purification.

Analyte solutions were made in methanol, with the flavonoid glycoside and metal salt each added at $1.0 \times$ $10^{-5} \mathrm{M}$. The intensities from the collisional activated dissociation (CAD) experiments are reported relative to the most intense peak in the spectrum, which is designated as $100 \%$. In collecting MS/MS and MS $^{3}$ data, the collision energy was increased until the parent ion was reduced to $5-10 \%$ intensity. The normalized collision energy range was $18-25 \%$; this corresponds to approximately $0.8-1.1 \mathrm{~V}$ according to the equations supplied by ThermoFinnigan. The isolation window was typically $2 \mathrm{~m} / \mathrm{z}$, though for some complexes, particularly those involving glycosides of quercetin, it was necessary to increase the window to as much as $4 \mathrm{~m} / \mathrm{z}$ to obtain a stable signal. All tables list fragments down to $2 \%$ intensity, but we consider $5 \%$ to be a lower limit for reliability of isomer differentiation. Post-CAD solvent adducts (e.g., [fragment ion $\left.+\mathrm{CH}_{3} \mathrm{OH}\right]^{+}$) were apparent in several instances, but as their appearance is dependent on the background pressure and the contents of the trap, we do not regard them as reliable diagnostic products, and generally exclude them from our analysis.

\section{Results and Discussion}

Until the recent development and application of metal complexation strategies, flavonoids have generally been analyzed as protonated or deprotonated species by mass spectrometry. Greater sensitivity has been reported in the negative ion mode than in the positive ion mode [21, 30, 31, 38], a factor attributed to the substantial acidities of flavonoids and the ease of deprotonation due to their multiple hydroxyl groups. However, the 
MW=432<smiles>O=c1cc(-c2ccc(O)cc2)oc2cc(OC3CCCCC3)cc(O)c12</smiles>

apigenin-7-O-glucoside flavone<smiles>O=c1cc(-c2ccc(O)cc2)oc2cc(O)c(Cl)c(O)c12</smiles>

isovitexin (apigenin-6-C-glucoside) flavone<smiles>O=c1cc(-c2ccc(O)cc2)oc2c(Cl)c(O)cc(O)c12</smiles>

vitexin

(apigenin-8-C-glucoside) flavone<smiles>COc1cc(O)c2c(=O)cc(-c3ccc(O)c(O)c3)oc2c1</smiles>

luteolin-7-O-glucoside<smiles>O=c1cc(-c2ccc(O)c(O)c2)oc2c(Cl)c(O)cc(O)c12</smiles>

orientin

(luteolin-8-C-glucoside) flavone flavone<smiles>[14CH3]Oc1c(-c2ccc(O)c(O)c2)oc2cc(O)cc(O)c2c1=O</smiles>

quercitrin (quercetin-3-O-rhamnoside) flavonol

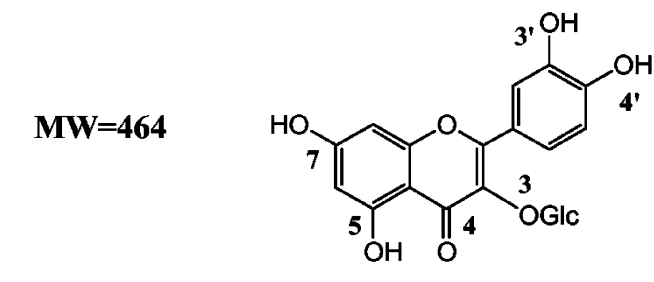

quercetin-3-O-glucoside flavonol<smiles>COc1ccc(-c2oc3cc(O)cc(O)c3c(=O)c2O)cc1O</smiles>

spiraeoside (quercetin-4'-O-glucoside) flavonol<smiles>COc1cc(O)c2c(=O)c(O)c(-c3ccc(O)c(O)c3)oc2c1</smiles>

quercetin-7-O-glucoside flavonol<smiles>O=C1CC(c2ccc(O)cc2)Oc2cc(Cl)cc(O)c21</smiles>

naringenin-7-O-glucoside flavanone

Glc=beta-D-glucopyranosyl

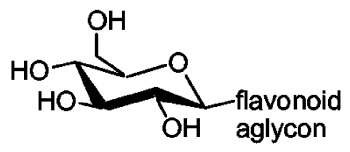

$M W=478$<smiles>COc1cc(-c2oc3cc(O)cc(O)c3c(=O)c2OC)ccc1O</smiles>

isorhamnetin-3-O-glucoside flavonol

$\mathrm{Rha}=$ alpha-L-rhamnopyranosyl

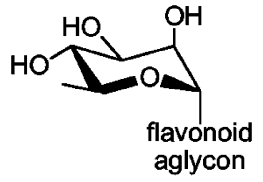

Figure 1. The structures of the flavonoid glycosides included in this study. 


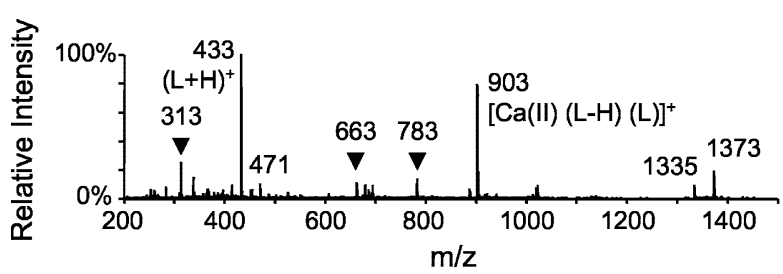

Figure 2. Full scan spectrum of isovitexin and $\mathrm{Ca}(\mathrm{II})$. $\mathrm{L}=$ isovitexin. 0,2 cross-ring cleavages of $\mathrm{m} / \mathrm{z} 433$ and 903 are represented by a filled triangle. Other minor ions include 471: [Ca(II) $(\mathrm{L}-\mathrm{H})]^{+} ; 1335:\left[\mathrm{Ca}(\mathrm{II})(\mathrm{L}-\mathrm{H}) \mathrm{L}_{2}\right]^{+} ; 1373$ : [2 $\left.\mathrm{Ca}(\mathrm{II})(\mathrm{L}-\mathrm{H})_{3}\right]^{+}$.

CAD spectra of deprotonated flavonoid glycosides generally show few fragments, and are therefore not particularly useful for isomer differentiation. The most successful and confident isomer differentiation results in unique fragment ions for different isomers, although sometimes differences in ratios or distributions of fragment ions may be considered. Our goal was to develop a simple but robust method based on metal complexation and CAD for differentiation of flavonoid glucosides. Five metals, $\mathrm{Ca}(\mathrm{II}), \mathrm{Mg}(\mathrm{II}), \mathrm{Co}(\mathrm{II}), \mathrm{Ni}(\mathrm{II})$, and $\mathrm{Cu}$ (II), were evaluated for their ability to form complexes of the type $[\mathrm{M}(\mathrm{II})(\mathrm{L})(\mathrm{L}-\mathrm{H})]^{+}$and give diagnostic fragmentation patterns upon CAD. These results are discussed in detail in this work.

Studies have suggested that certain structural features are required for metal chelation by flavonoids. Proposed chelation sites include the 4-keto and 5-OH groups, the 4-keto and 3-OH groups, and the 3 '-OH and $4^{\prime}$-OH groups [72-76]. It is possible that more than one of these sites is active for flavonoids containing multiple binding groups. Every flavonoid glycoside in this study contains at least the 4-keto and 5-OH groups, allowing them to form metal complexes. Flavonoids lacking suitable chelation sites are unlikely to be amenable to metal complexation.

The complexes were produced from methanolic solutions containing 1:1 flavonoid glycoside/metal salt. No $\mathrm{pH}$ adjustment was performed on the analyte solutions. Under these conditions, the flavonoid glycosides formed 1:1 and 2:1 analyte/metal complexes of the type $[\mathrm{M}(\mathrm{II})(\mathrm{L}-\mathrm{H})]^{+}$and $[\mathrm{M}(\mathrm{II})(\mathrm{L})(\mathrm{L}-\mathrm{H})]^{+}$. Additionally, larger complexes were occasionally observed, including $3: 1,3: 2,4: 1$, and $4: 2$ analyte:metal stoichiometries. Some of these stoichiometries have been previously reported for copper and iron complexes of flavonoids [77]. Figure 2 shows the full scan mass spectrum of isovitexin and $\mathrm{Ca}(\mathrm{II})$, which form complexes with several different stoichiometries. The intensities of the 1:1 analyte/metal complexes are often very low, and CAD results in complicated mass spectra that often do not assist in compound identification. In contrast, the 2:1 complexes are more intense, and they give simple CAD spectra with easily-assigned fragments and a variety of dissociation pathways for structural determination. One possible structure for the 2:1 complexes is shown in Schemes $\mathbf{1}$ and 2. The complexes involve a doublycharged metal ion, one deprotonated flavonoid glyco- side and one neutral flavonoid glycoside. The chelation site is speculative and likely to be compound-dependent; and it is even possible that more than one structure forms for some analyte/metal complexes. Likewise, the coordination geometry of the complexes is unknown, though particular metals are known to favor certain geometries over others. Common dissociation routes seen for O-glucosyl flavonoid complexes include loss of one or two glucose residues, loss of an entire flavonoid glucoside molecule, and loss of the aglycon portion of one flavonoid glucoside (Scheme 1). Fragmentation pathways most characteristic of C-glucosyl flavonoid complexes include dehydration and crossring cleavages of the glucose moiety, resulting in losses of $90 \mathrm{u}$ or $120 \mathrm{u}$ (Scheme 2). Figure 3 more clearly shows which bonds are broken as the result of various crossring cleavages. These types of losses are well-known for C-glycosyl flavonoids, and were discussed in detail by Waridel et al. [29]. The loss of one or more water molecules observed with some C-glycosyl flavonoid complexes has also been reported in mass spectral analysis of deprotonated C-glycosyl flavonoids [17, 29, 38] and alternate structures for these ions have been proposed [17].

A direct comparison of the CAD mass spectra of deprotonated flavonoid glycosides and flavonoid glycoside/metal complexes illustrates the advantage of the metal complexation strategy. Figure 4 shows CAD mass spectra obtained for three isomeric deprotonated flavonoid glucosides and the corresponding $\mathrm{Mg}$ (II) complexes. The three compounds are all quercetin derivatives, with the glucose moiety attached at either the 3 , $4^{\prime}$, or 7 position on the flavonoid skeleton. The dominant fragmentation pathway of the deprotonated flavonoid glucosides is the loss of the glucose moiety, $-162 \mathrm{u}$ (Figure 4a). Both quercetin-3-O-glucoside and quercetin7-O-glucoside undergo a radical loss of the glucose moiety $(-163 \mathrm{u})$ and a cross-ring saccharide cleavage resulting in loss of $120 \mathrm{u}$, but the latter pathway results in fragment ions with less than $5 \%$ intensity. The few fragmentation pathways of deprotonated flavonoid glucosides are insufficient for differentiating these isomers, which differ only by the position of glycosylation. Similarly, protonated flavonoid glycosides and sodium adducts of the form $[\mathrm{Na}(\mathrm{L})]^{+}$and $\left[\mathrm{Na}(\mathrm{L})_{2}\right]^{+}$produce few fragments upon dissociation, and in many cases isomer differentiation is not possible (data not shown). In contrast, alkaline earth metal complexes show greater variety in their dissociation pathways. The CAD mass spectra of the magnesium complexes exhibit distinctive features for each of the three isomers (Figure $4 \mathrm{~b}$ ). The major fragmentation pathway is loss of the glucose residue for all three complexes. This is the only significant fragment observed for the quercetin-3-O-glucoside complex. The $[\mathrm{Mg}(\mathrm{II})$ (spiraeoside $-\mathrm{H})$ (spiraeoside) $]^{+}$complex additionally undergoes loss of an aglycon unit and elimination of one flavonoid glycoside molecule, providing sufficient differentiation from quercetin-3-O-glucoside. The quercetin-7-O-glucoside complex displays a unique ion at $m / z 831$, corresponding to a 0,2 cross-ring cleav- 
<smiles>COc1cc(O[C@H]2O[C@H](CO)[C@@H](O)[C@H](O)[C@H]2O)cc2oc(-c3ccc(O)c(O)c3)cc(=O)c12</smiles>

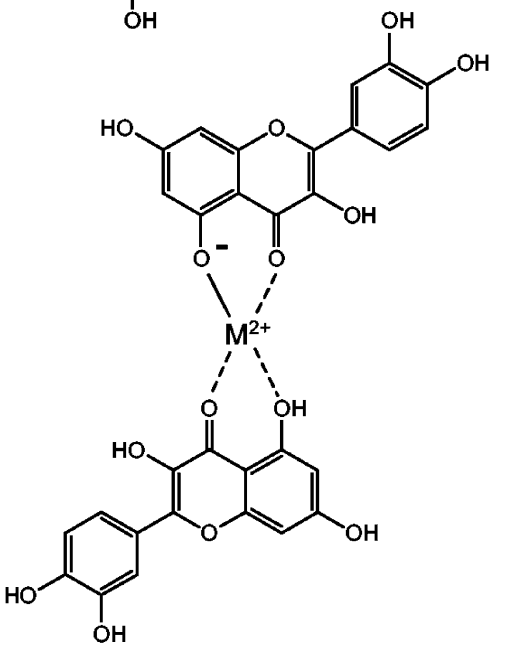

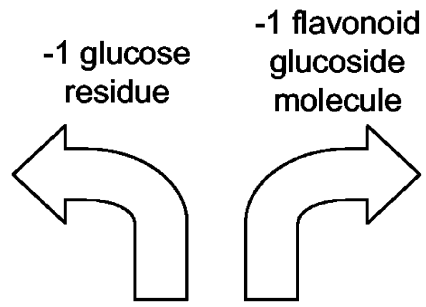

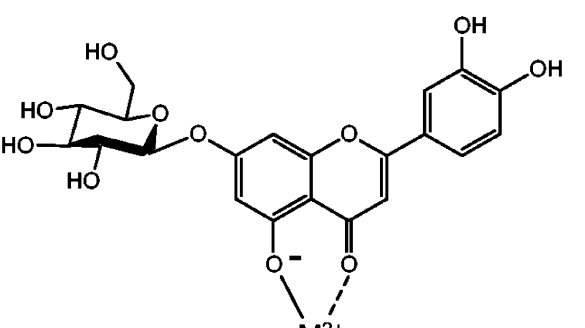

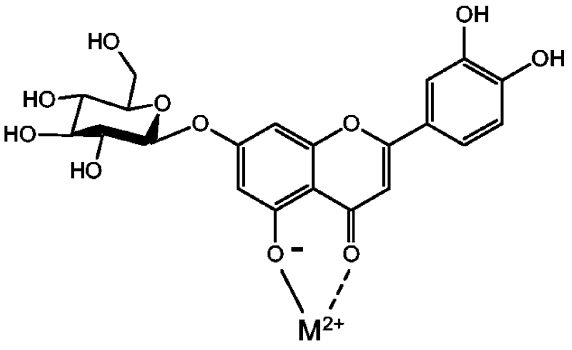<smiles>O=c1cc(-c2ccc(O)c(O)c2)oc2cc(OC(OCCO)[C@H](O)CO)cc([O-])c12</smiles>

Scheme 1. Speculative structures of fragment ions commonly observed for metal complexes of O-glucosyl flavonoids (luteolin-7-O-glucoside shown as example).

age of one glucose moiety ( $-120 \mathrm{u}, 20 \%$ intensity). All three complexes display unique CAD mass spectra that allow differentiation of the flavonoid glucosides. Furthermore, the pattern of fragments observed for many of the metal complexes are strongly dependent on the site of glycosylation. Figure 5 shows the CAD mass spectra of the four 7-O-glucosyl flavonoids complexed to $\mathrm{Mg}(\mathrm{II})$. The types of fragments and their relative intensities are very similar, despite differences in the aglycon structure. This example demonstrates that the dissociation patterns of the magnesium complexes are correlated with the glycosylation site, and can be used to determine this information for unknown flavonoid glucosides.

In the following sections, the CAD mass spectra of the calcium, magnesium, cobalt, nickel, and copper complexes are discussed, with an emphasis on the diagnostic utility of the fragmentation patterns for glycosylation site determination.

\section{CAD of Calcium Complexes}

The list of fragments observed upon CAD of the [Ca(II) (L) $(\mathrm{L}-\mathrm{H})]^{+}$complexes is shown in Table 1 . There is a striking difference in the fragmentation pathways of the calcium complexes of O-glucosyl and C-glucosyl flavonoids that allows them to be readily differentiated. For all of the O-glucosyl flavonoids, the most intense fragment results from the elimination of one glucose residue. In contrast, the complexes of the C-glucosyl flavonoids do not display this loss. Their dominant dissociation pathway is a 0,2 cross-ring cleavage of one glucose moiety, resulting in the loss of $120 \mathrm{u}$. Precise identification of the glycosylation site is possible, following the strategy outlined in Scheme 3. The complexes involving 7-O-glucosyl flavonoids are the only ones to display both the loss of an intact glucose moiety and a 0,2 cross-ring cleavage of one glucose moiety. The 4 '-O-glucosyl flavonoids are differentiated from the 3-O-glucosyl flavonoids by minor losses of one flavonoid glucoside molecule and one aglycon unit from the metal complex. However these fragment ions are not always above 5\% intensity. For more confident differentiation, a secondary stage of CAD was performed to further interrogate the fragment ion stemming from the loss of one glucose moiety. For the $4^{\prime}$-O-glucosyl flavonoid complexes, the resulting $\mathrm{MS}^{3}$ spectra display a cluster of fragment ions associated 
<smiles>O=CCc1c(O)cc2oc(-c3ccc(O)cc3)cc(=O)c2c1O[W]([O-])Oc1c(O)c(O)cc2oc(-c3ccc(O)cc3)cc(=O)c12</smiles>

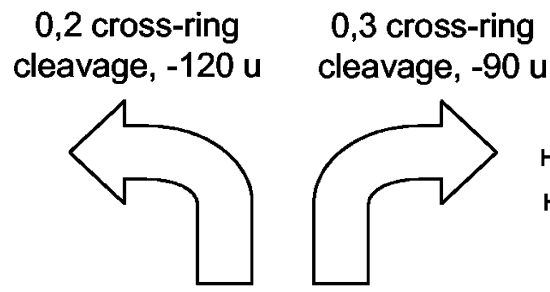

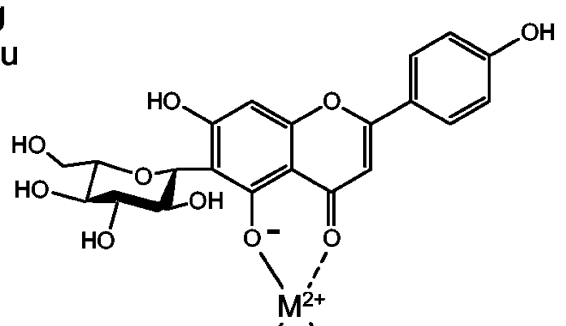

HO

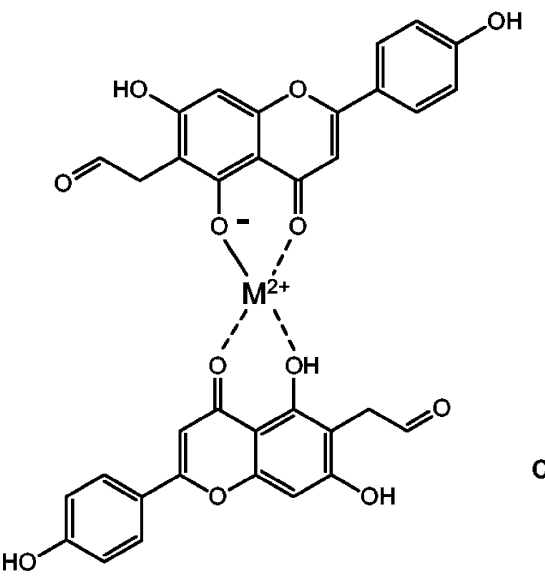<smiles>COc1c(CC(O)C=O)c(O)cc2oc(-c3ccc(O)cc3)cc(=O)c12</smiles><smiles>O=c1cc(-c2ccc(O)cc2)oc2cc(O)c([C@H]3O[C@@H](CO)[C@H](O)[C@H](O)[C@H]3O)c(O)c12</smiles>

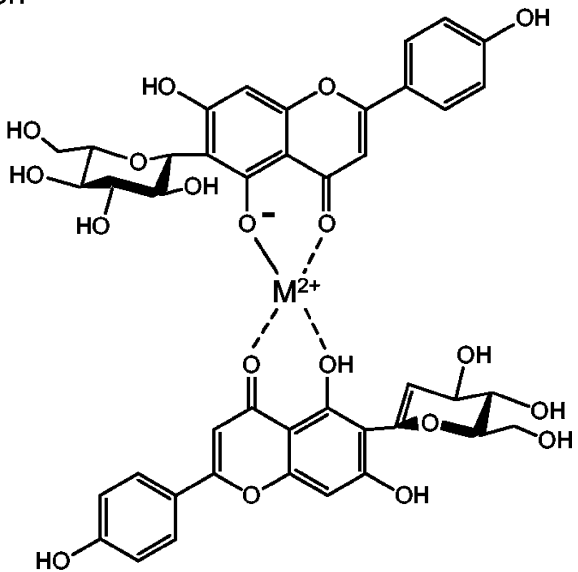

Scheme 2. Speculative structures of fragment ions commonly observed for metal complexes of C-glucosyl flavonoids (isovitexin shown as example).

with the loss of one flavonoid glucoside molecule, a pathway that is absent or very weak for the 3-Oglucosyl flavonoid complexes (Figure 6). The ion stemming from the loss of the flavonoid glucoside is not itself detected, but several post-dissociation solvent adducts are clearly observed, including the adduction of one or two methanol or water molecules.

The ion labeled as " $4-\mathrm{F}$ " in Table 1 appears in the

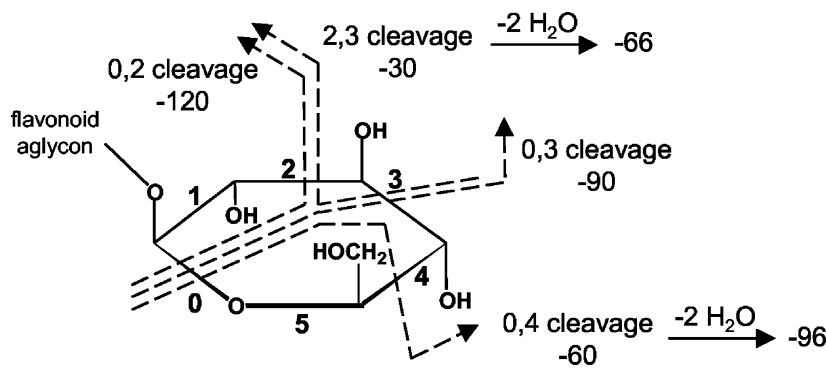

Figure 3. Selected cross-ring cleavages of the glucose residue, adapted from [29].
CAD spectra of some of the calcium complexes. This ion stems from the parent species $\left[2 \mathrm{Ca}(\mathrm{II})(\mathrm{L}-\mathrm{H})_{2}(\mathrm{~L})_{2}\right]^{2+}$. This $4: 2$ analyte/calcium complex has the same mass/ charge ratio as the desired 2:1 complex, so both species are isolated simultaneously in the trap prior to dissociation. Upon activation the 4:2 complex loses one neutral flavonoid glucoside molecule to form [2 Ca(II) (L-H) $(\mathrm{L})]^{2+}$. Although this dissociation pathway is observed for both 4'-O-glucosyl flavonoids in this study, it is not a useful diagnostic tool as it appears in the spectra of some 3-O- and 7-O-glucosyl flavonoid complexes as well. There may also be a concentration dependence that influences the ratio of 4:2 versus 2:1 complexes. An excessive amount of the 4:2 complex could mask the fragments from the 2:1 complex, which would complicate identification of the flavonoid glucoside.

The $\mathrm{Ca}$ (II) complexes of the 6-C- and 8-C-glucosyl flavonoids display nearly identical CAD mass spectra, necessitating the use of $\mathrm{MS}^{3}$ for differentiation. A further stage of fragmentation of the 0,2 cross-ring cleav- 

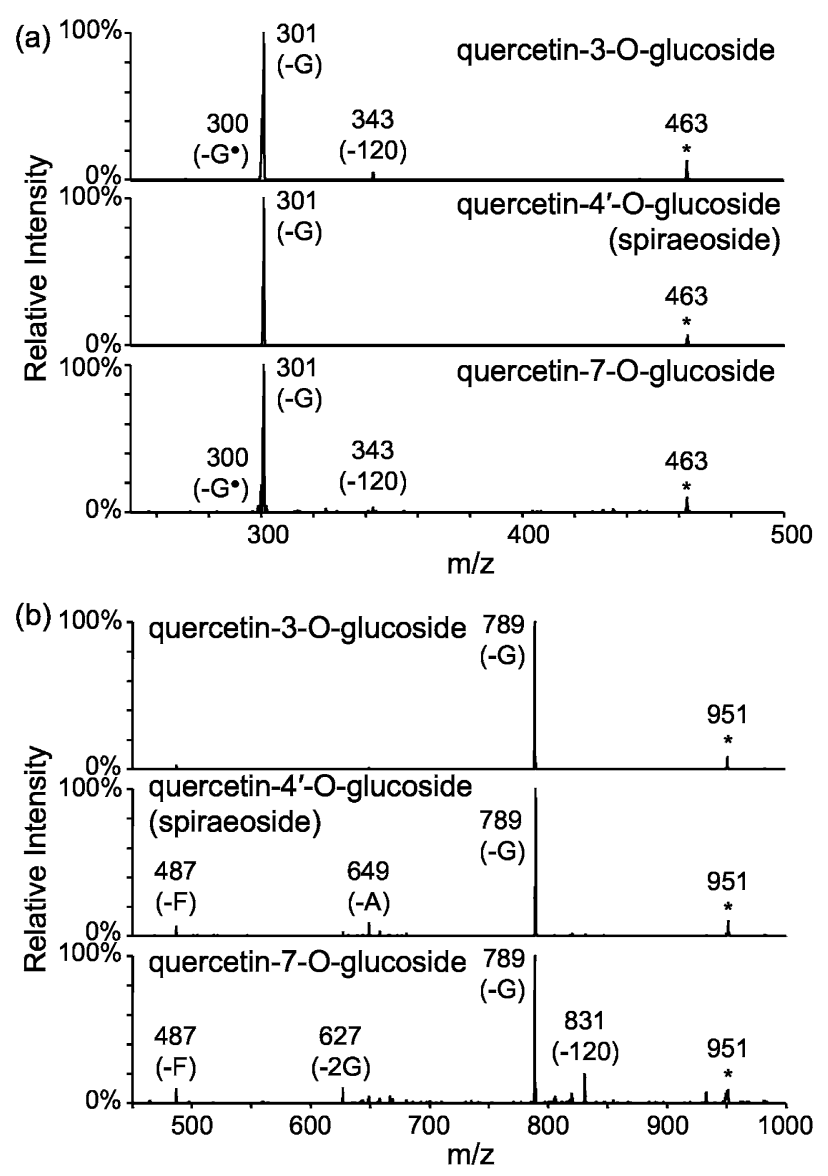

Figure 4. CAD spectra of quercetin monoglucosides, $\mathrm{MW}=464$. (a) Fragments obtained from deprotonated analytes. (b) Fragments obtained from $[\mathrm{Mg}(\mathrm{II})(\mathrm{L}-\mathrm{H})(\mathrm{L})]^{+}$. Fragmentation pathways are labeled as: $-\mathrm{G}$ (loss of a glucose residue), $-2 \mathrm{G}$ (loss of two glucose residues), $-\mathrm{G}^{*}$ (loss of a glucose radical residue), $-\mathrm{A}$ (loss of aglycon portion), $-\mathrm{F}$ (loss of one flavonoid glucoside molecule).

age product results in clear spectral differences between these two categories of flavonoid glucosides. The loss of $312 \mathrm{u}$ (for vitexin and isovitexin) or $328 \mathrm{u}$ (for orientin and homoorientin) corresponds to the elimination of the remainder of the flavonoid glucoside molecule left after the initial cross-ring cleavage. This fragmentation product, indicated by "-(F-120)" in Table 1, is only significant for the 8-C-glucosyl flavonoids. Another low-intensity diagnostic ion for 8-C-glucosylation is the 0,4 cross-ring cleavage product $(-60 \mathrm{u})$.

\section{CAD of Magnesium Complexes}

Based on the CAD mass spectra, the $[\mathrm{Mg}(\mathrm{II})(\mathrm{L})(\mathrm{L}-\mathrm{H})]^{+}$ complexes offer the best and most complete identification and differentiation of all five categories of flavonoid glucosides without the need for $\mathrm{MS}^{3}$ analysis. Figure 7 shows the CAD spectra of the $\mathrm{Mg}$ (II) complexes involving flavonoid glucosides with molecular weight 448 . Each analyte is glycosylated at a different site, and the spectra provide an unambiguous means to

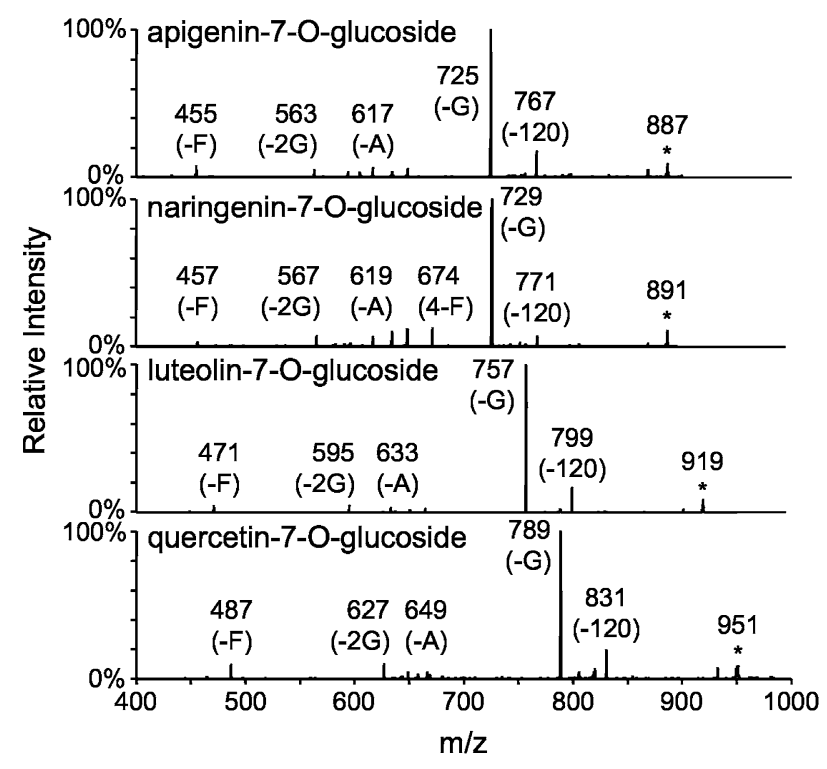

Figure 5. CAD spectra of $[\mathrm{Mg}(\mathrm{II})(\mathrm{L}-\mathrm{H})(\mathrm{L})]^{+}$complexes of 7-O-glucosyl flavonoids. Fragmentation pathways are labeled as: $-\mathrm{G}$ (loss of a glucose residue), $-2 \mathrm{G}$ (loss of two glucose residues), -A (loss of aglycon portion), $-\mathrm{F}$ (loss of one flavonoid glucoside molecule), 4-F ([2 Mg(II) $\left.\left.(\mathrm{L}-\mathrm{H})_{2}(\mathrm{~L})_{2}\right]^{2+}-\mathrm{L}\right)$.

differentiate these five isomers, and allow determination of the glycosylation site based on the diagnostic ions discussed below. Table 2 lists the major losses from these complexes. Loss of the glucose moiety is indicative of O-glucosylation, while the 0,2 cross-ring cleavage of glucose $(-120 \mathrm{u})$ is the most significant fragmentation pathway for the C-glucosyl flavonoid complexes. Like the calcium complexes, the magnesium complexes offer a means to distinguish the three O-glucosylation sites (Scheme 4). Once O-glucosylation has been determined, the 7-O glucosylation site can be confirmed by the presence of the 0,2 cross-ring cleavage pathway. 3-O-glucosyl flavonoid complexes display no significant losses other than that of the glucose moiety, whereas the 4'-O-glucosyl flavonoid complexes also lose an aglycon residue and an entire flavonoid glucoside molecule. These diagnostic ions are sufficiently intense that $\mathrm{MS}^{3}$ is not necessary for differentiating the 3-O- and 4'-O-glucosyl flavonoids. The CAD mass spectra of the magnesium complexes also allow differentiation of the two C-glucosylation positions. Complexes involving 6-C-glucosyl flavonoids have a prominent dehydration pathway that involves the loss of up to three water molecules, whereas 8-C-glucosyl flavonoid complexes display only a minor loss of one water molecule. Another indicator of 6-C-glucosylation is the unique fragment resulting from the combination of the 0,2 cross-ring cleavage $(-120 \mathrm{u})$ and dehydration. Diagnostic ions for 8-C-glucosyl flavonoid complexes include the 0,3 cross-ring cleavage $(-90 \mathrm{u})$, and the 0,2 cleavage of both glucose moieties.

One concern in relying on the analysis of $[\mathrm{Mg}$ (II) $(\mathrm{L}-\mathrm{H})(\mathrm{L})]^{+}$complexes for isomer differentiation is the possible isobaric overlap from $\left[\mathrm{Na}(\mathrm{L})_{2}\right]^{+}$species, which 
Table 1. CAD losses from $[\mathrm{Ca}(\mathrm{II})(\mathrm{L}-\mathrm{H})(\mathrm{L})]^{+}$complexes

\begin{tabular}{|c|c|c|c|c|c|c|c|c|c|c|c|c|}
\hline \multicolumn{13}{|c|}{ MS/MS } \\
\hline $\begin{array}{l}\text { Glycosylation } \\
\text { site }\end{array}$ & $\begin{array}{l}\text { Flavonoid } \\
\text { glucoside }\end{array}$ & & $-G^{a}$ & $-F$ & $-f$ & & $-2 \mathrm{G}$ & $4-F$ & $(\mathrm{~F}+\mathrm{H})^{+}$ & -120 & $-(2 \times 120)$ & -90 \\
\hline \multirow[t]{3}{*}{$3-0$} & kaempferol-3-gl & & $100^{b}$ & - & - & & - & - & - & - & - & - \\
\hline & quercetin-3-gl & & 100 & - & - & & - & - & - & - & - & - \\
\hline & isorhamnetin-3- $\mathrm{c}$ & & 100 & - & - & & - & 6 & - & - & - & - \\
\hline \multirow[t]{2}{*}{$4^{\prime}-0$} & luteolin-4'-gl & & 100 & 8 & 5 & & - & 25 & - & - & - & - \\
\hline & spiraeoside & & 100 & 4 & 4 & & - & 19 & - & - & - & - \\
\hline \multirow[t]{4}{*}{$7-0$} & apigenin-7-gl & & 100 & 3 & - & & 5 & - & 6 & 15 & - & - \\
\hline & naringenin-7-gl & & 100 & 5 & - & & - & 9 & - & 8 & - & - \\
\hline & luteolin-7-gl & & 100 & 2 & - & & 6 & - & 5 & 15 & - & - \\
\hline & quercetin-7-gl & & 100 & 4 & - & & - & - & 3 & 12 & - & - \\
\hline \multirow[t]{2}{*}{$6-\mathrm{C}$} & isovitexin & & - & - & - & & - & - & - & 100 & 3 & 8 \\
\hline & homoorientin & & - & - & - & & - & - & - & 100 & 2 & 8 \\
\hline \multirow[t]{2}{*}{$8-\mathrm{C}$} & vitexin & & - & - & - & & - & - & - & 100 & 5 & 6 \\
\hline & orientin & & - & - & - & & - & - & - & 100 & - & 6 \\
\hline \multicolumn{13}{|c|}{$\mathrm{MS}^{3}$ on $-\mathrm{G}$ ion } \\
\hline $\begin{array}{l}\text { Glycosylation } \\
\text { site }\end{array}$ & \multicolumn{2}{|l|}{$\begin{array}{l}\text { Flavonoid } \\
\text { glucoside }\end{array}$} & \multicolumn{4}{|c|}{$-\mathrm{A}$} & \multicolumn{3}{|c|}{$-\mathrm{F}+$ adducts } & & & \\
\hline \multirow[t]{3}{*}{$3-0$} & \multirow{3}{*}{\multicolumn{2}{|c|}{$\begin{array}{l}\text { kaempferol-3-gl } \\
\text { quercetin-3-gl } \\
\text { isorhamnetin-3-gl }\end{array}$}} & \multicolumn{4}{|c|}{100} & \multicolumn{3}{|c|}{ - $\quad-$} & & & \\
\hline & & & \multicolumn{2}{|c|}{12} & \multicolumn{2}{|l|}{100} & - & \multicolumn{2}{|c|}{-} & & & \\
\hline & & & \multicolumn{2}{|c|}{17} & \multicolumn{2}{|l|}{100} & - & \multicolumn{2}{|c|}{-} & & & \\
\hline \multirow[t]{2}{*}{$4^{\prime}-0$} & luteolin-4'-gl & & \multirow{2}{*}{\multicolumn{2}{|c|}{$\begin{array}{r}100 \\
12\end{array}$}} & \multicolumn{2}{|l|}{80} & 3 & \multicolumn{2}{|c|}{ variable } & & & \\
\hline & spiraeoside & & & & 100 & & 6 & \multicolumn{2}{|c|}{ variable } & & & \\
\hline \multicolumn{13}{|c|}{$\mathrm{MS}^{3}$ on -120 ion } \\
\hline $\begin{array}{l}\text { Glycosylation } \\
\text { site }\end{array}$ & $\begin{array}{l}\text { Flavonoid } \\
\text { glucoside }\end{array}$ & -120 & & $-(F-120$ & & -60 & & $\begin{array}{l}(F-120) \\
\text { and } 60]\end{array}$ & $-\mathrm{H}_{2} \mathrm{O}$ & & & \\
\hline$\overline{6-C}$ & isovitexin & 100 & & 3 & & - & & - & 3 & & & \\
\hline & homoorientin & 100 & & 3 & & - & & - & 4 & & & \\
\hline $8-C$ & vitexin & 100 & & 37 & & 6 & & 8 & - & & & \\
\hline & orientin & 100 & & 21 & & 6 & & 7 & - & & & \\
\hline
\end{tabular}

${ }^{a}$ Fragments are abbreviated as $-\mathrm{G}$ : loss of one glucose residue, $-\mathrm{F}$ : loss of one flavonoid glucoside molecule, $-\mathrm{A}$ : loss of aglycon portion, $-2 \mathrm{G}$ : loss of two glucose residues, $4-\mathrm{F}$ : loss of one flavonoid glucoside molecule from $\left[2 \mathrm{Ca}(\mathrm{II})(\mathrm{L}-\mathrm{H})_{2}(\mathrm{~L})_{2}\right]^{2+},(\mathrm{F}+\mathrm{H})^{+}:[\mathrm{L}+\mathrm{H}]^{+},-(\mathrm{F}-120)$ : loss of remainder of the fragmented flavonoid glucoside molecule.

${ }^{\text {b}}$ The relative intensity of each fragment ion is an average of 2 to 4 experiments carried out on different days.

can lead to misidentification due to different fragmentation pathways for the sodium-cationized species. Although sodium adducts are routinely observed in the ESI mass spectra of flavonoid glycosides due to the ubiquitous presence of sodium in the environment, addition of a magnesium salt at the $10^{-5} \mathrm{M}$ level usually results in formation of $\mathrm{Mg}(\mathrm{II})$ complexes that significantly outweigh the contribution from sodium adducts for the flavonoid glucosides in this study. Increasing the magnesium concentration solves the problem in cases when there is a significant contribution from the sodium-cationized species.

\section{CAD of Transition Metal Complexes}

Despite the efficient formation of transition metal complexes of the type $\left[\mathrm{M}^{\mathrm{II}}(\mathrm{L}-\mathrm{H})(\mathrm{L})\right]^{+}$where $\mathrm{M}=\mathrm{Co}, \mathrm{Ni}$, or $\mathrm{Cu}$, none of these complexes permitted complete identification of all five glycosylation sites. For cobalt and nickel complexes, which have very similar dissociation pathways, O-glucosylation and C-glucosylation can be differentiated based on the presence or absence of the ion stemming from the loss of an intact glucose residue. The 6-C-glucosyl flavonoid complexes are characterized by a very prominent dehydration pathway involving the loss of up to three water molecules, allowing differentiation from 8-C-glucosyl flavonoid complexes in a manner similar to the magnesium complexes. The 7-O-glucosyl flavonoids can also be identified, as they are the only O-glucosyl flavonoids whose metal complexes dissociate via the 0,2 cross-ring cleavage pathway. However, neither cobalt nor nickel complexation provides sufficient differentiation of 3-O- and 4'-Oglucosyl flavonoids, even when further stages of CAD are performed on the most prominent fragment ions.

The copper complexes are even less useful for locating the glycosylation site. The dissociation behavior of some of the copper complexes is strongly dependent on the structure of the aglycon portion of the flavonoid glucoside. In several cases, increasing numbers of hydroxyl groups on the aglycon greatly intensifies radical losses in a manner similar to that reported by Hvattum 


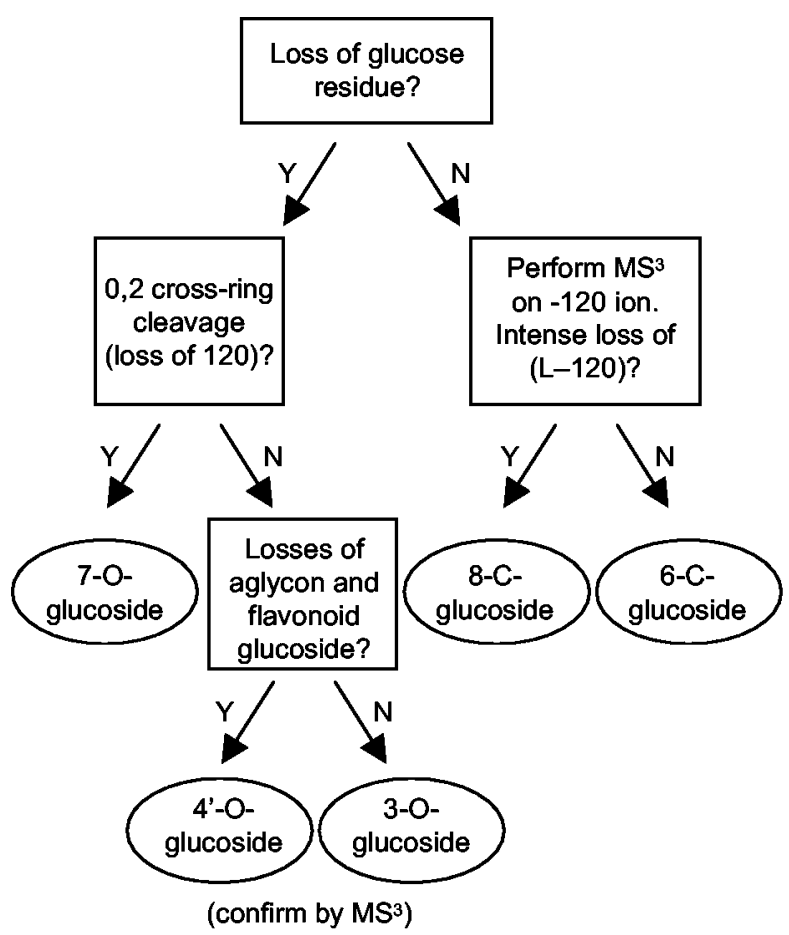

Scheme 3. Determination of glycosylation site by Ca complexation.

and Ekeberg for deprotonated flavonoid glycosides [24]. As a result, there were not consistent fragmentation patterns indicative of the glycosylation site.

\section{The Effect of Saccharide Identity}

To determine the impact of saccharide identity on the fragmentation patterns observed for the metal complexes, a 3-O-glycosyl flavonoid containing rhamnose rather than glucose was studied. Quercitrin is easily distinguished from the other flavonoid glycosides by every complexation mode described in this paper because it, like the other O-glycosyl flavonoids, readily loses the saccharide unit upon dissociation of the metal complexes. As rhamnose is a deoxyhexose, the loss of $146 \mathrm{u}$ (instead of $162 \mathrm{u}$ ) is sufficient to differentiate this compound from isomeric flavonoid glycosides. Despite this easy means of identification, we were interested in determining whether a flavonoid rhamnoside complex would dissociate by pathways similar to those of the glucosides. The fragmentation pathways from quercitrin/metal complexes were thus compared to the complexes of the flavonoid glucosides.

There were a number of differences in the spectra of the complexes involving quercitrin. One example is the CAD spectrum of quercitrin/ $\mathrm{Ni}$ (II) complexes, in which the loss of one aglycon unit is a much more significant fragmentation pathway than for complexes of the 3-Oglucosyl flavonoids (Figure 8a). Comparison of the $\mathrm{MS}^{3}$ results, where the parent ion is the 2:1 flavonoid glycoside/ $\mathrm{Ni}(\mathrm{II})$ complex after the loss of one saccharide

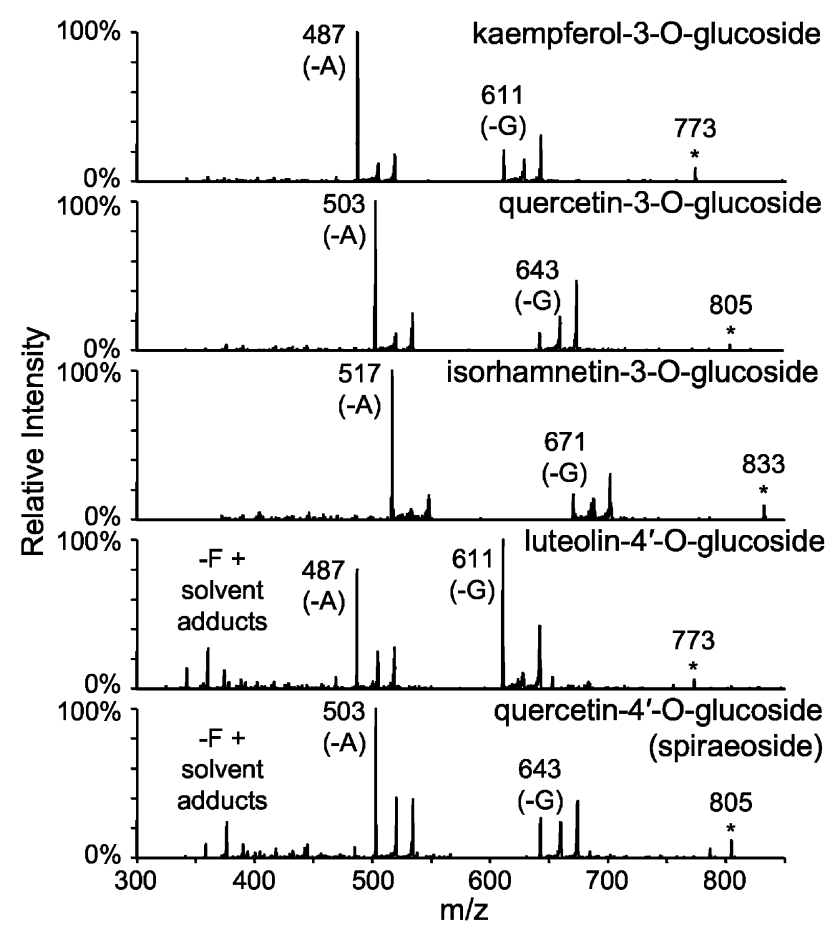

Figure 6. $\mathrm{MS}^{3}$ spectra of analyte/Ca(II) complexes involving 3-O- and 4'-O-glucosyl flavonoids. The second stage of CAD was performed on the ion stemming from the loss of one glucose residue from $[\mathrm{Ca}(\mathrm{II})(\mathrm{L}-\mathrm{H})(\mathrm{L})]^{+}$. Fragmentation pathways are labeled as: $-\mathrm{G}$ (loss of a glucose residue), -A (loss of aglycon portion), $-\mathrm{F}$ (loss of one flavonoid glucoside molecule).

moiety, reveals even more striking differences (Figure $8 b)$. The dehydration pathway is much more significant for the quercitrin complex, which shows intense losses of one and two water molecules, compared to a minor loss of just one water molecule for the analogous glucoside complexes. The cross-ring cleavages are also more significant and more varied. (Because rhamnose is a deoxyhexose, the mass of the cleaved portion of the saccharide is $16 \mathrm{u}$ less than it would be for glucose.) The 0,2 cleavage, seen at $703 \mathrm{u}$ is the most dominant fragment for the quercitrin/ $\mathrm{Ni}(\mathrm{II})$ complex, but the corresponding cleavage $(-120 \mathrm{u})$ is minor for the two flavonoid glucoside complexes. The quercitrin complex also displays a 0,1 cleavage $(-134 \mathrm{u})$ and a 0,4 cleavage followed by loss of two water molecules $(-80 \mathrm{u})$, neither of which is observed for the glucoside complexes. Furthermore, the quercitrin complex does not undergo a significant loss of an aglycon unit, which is the dominant loss for the three glucoside complexes. These results show that both the identity of the saccharide and its location may play important roles in determining the fragmentation pathways of these metal complexes.

\section{Conclusions}

Dissociation of protonated, deprotonated or sodiumcationized flavonoid monoglucosides does not always 


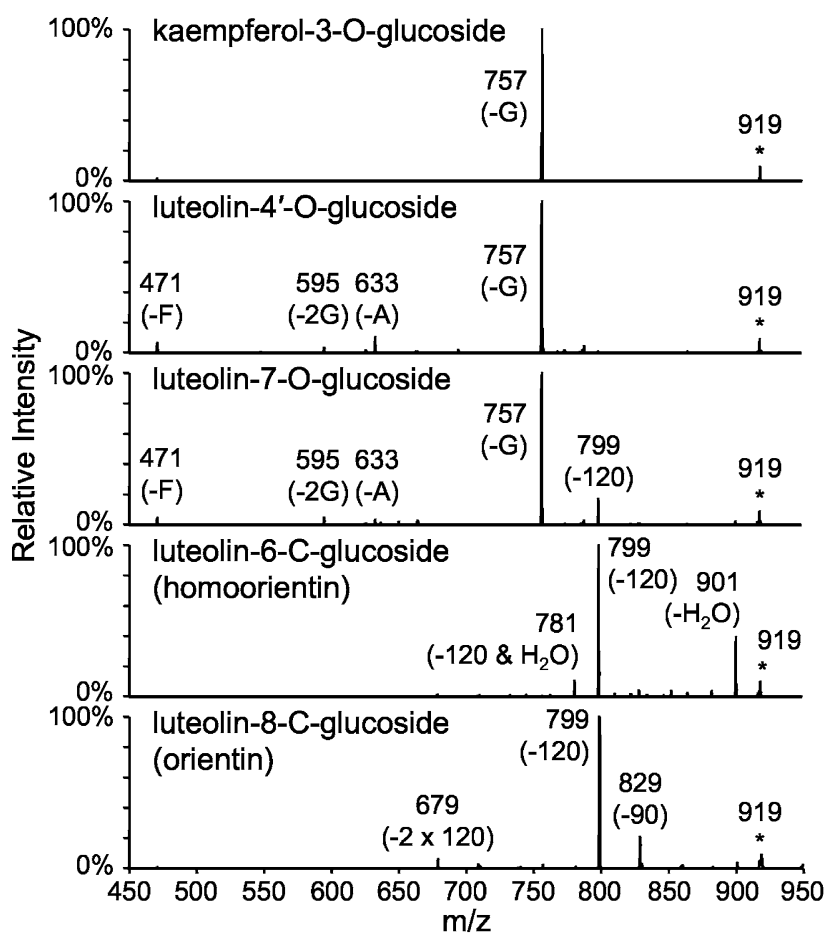

Figure 7. CAD spectra of $[\mathrm{Mg}(\mathrm{II})(\mathrm{L}-\mathrm{H})(\mathrm{L})]^{+}$complexes involving isomeric monoglucosyl flavonoids glycosylated at five different positions. Fragmentation pathways are labeled as: $-\mathrm{G}$ (loss of a glucose residue), $-2 \mathrm{G}$ (loss of two glucose residues), $-\mathrm{A}$ (loss of aglycon portion), $-\mathrm{F}$ (loss of one flavonoid glucoside molecule).

provide sufficient diagnostic fragments for distinguishing isomers that differ only by their glycosylation site. An alternative approach is to form flavonoid glucoside/metal complexes of the type [M(II) (L) $(\mathrm{L}-\mathrm{H})]^{+}$which give a broader array of fragments for structural analysis. The dissociation pathways of the complexes are strongly dependent on the glycosylation site, offering a means to determine this important structural feature by mass spectrometry. Thir-

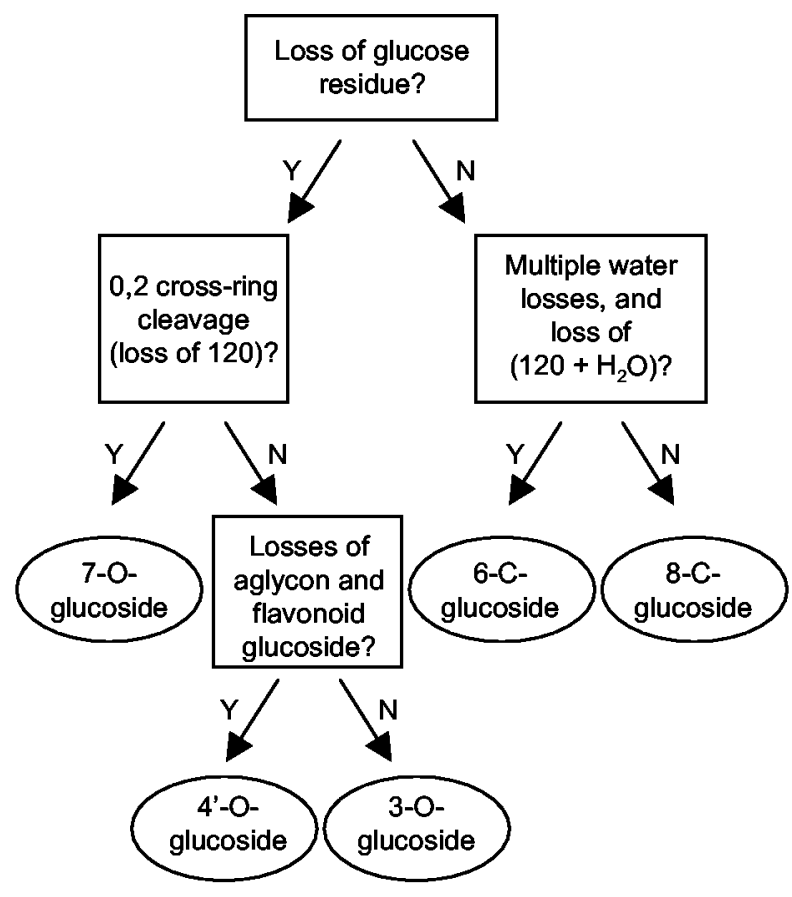

Scheme 4. Determination of glycosylation site by $\mathrm{Mg}$ complexation.

teen flavonoid glucosides were analyzed in conjunction with five metal ions. CAD of $\mathrm{Mg}(\mathrm{II})$ complexes resulted in distinctive fragmentation patterns that are indicative of five commonly observed flavonoid glycosylation sites. $\mathrm{Ca}$ (II) can also be used to differentiate the glycosylation site if $\mathrm{MS}^{3}$ is employed. These metal complexation strategies are effective for hydroxylated and methoxylated flavones, flavonols, and flavanones. Complexes involving $\mathrm{Co}(\mathrm{II}), \mathrm{Ni}(\mathrm{II})$, and $\mathrm{Cu}(\mathrm{II})$ were less successful because universal indicators of glycosylation position could not be found for all five glycosylation sites. Compar-

Table 2. CAD losses from $[\mathrm{Mg}(\mathrm{II})(\mathrm{L}-\mathrm{H})(\mathrm{L})]^{+}$complexes

\begin{tabular}{|c|c|c|c|c|c|c|c|c|c|c|c|c|c|c|c|}
\hline \multicolumn{16}{|c|}{$\mathrm{MS} / \mathrm{MS}$} \\
\hline $\begin{array}{l}\text { Glycosylation } \\
\text { Site }\end{array}$ & $\begin{array}{l}\text { Flavonoid } \\
\text { glucoside }\end{array}$ & $-\mathrm{G}^{\mathrm{a}}$ & $-F$ & $-\mathrm{A}$ & $-2 \mathrm{G}$ & $4-F$ & -120 & $-\mathrm{H}_{2} \mathrm{O}$ & $\begin{array}{r}-2 \\
\mathrm{H}_{2} \mathrm{O} \\
\end{array}$ & $\begin{array}{r}-3 \\
\mathrm{H}_{2} \mathrm{O} \\
\end{array}$ & $\begin{array}{c}-(120 \\
\left.\text { and } \mathrm{H}_{2} \mathrm{O}\right)\end{array}$ & $\begin{array}{r}-(2 \times \\
120)\end{array}$ & -66 & -90 & $\begin{array}{c}-(120 \\
\text { and } 90)\end{array}$ \\
\hline \multirow[t]{3}{*}{$3-0$} & kaempferol-3-gl & $100^{b}$ & - & - & - & - & - & - & - & - & - & - & - & - & - \\
\hline & quercetin-3-gl & 100 & - & - & - & - & - & - & - & - & - & - & - & - & - \\
\hline & isorhamnetin-3-gl & 100 & - & - & - & - & - & - & - & - & - & - & - & - & - \\
\hline \multirow[t]{2}{*}{$4^{\prime} \mathrm{O}$} & luteolin-4'-gl & 100 & 6 & 8 & 3 & - & - & - & - & - & - & - & - & - & - \\
\hline & spiraeoside & 100 & 6 & 8 & - & - & - & - & - & - & - & - & - & - & - \\
\hline \multirow[t]{4}{*}{$7-0$} & apigenin-7-gl & 100 & 5 & 5 & 4 & - & 20 & 5 & - & - & - & - & - & - & - \\
\hline & naringenin-7-gl & 100 & 3 & 7 & 8 & 11 & 8 & - & - & - & - & - & - & - & - \\
\hline & luteolin-7-gl & 100 & 2 & 3 & 5 & - & 16 & 2 & - & - & - & - & - & - & - \\
\hline & quercetin-7-gl & 100 & 10 & 5 & 9 & - & 20 & 5 & - & - & - & - & - & - & - \\
\hline \multirow[t]{2}{*}{$6-\mathrm{C}$} & isovitexin & - & - & - & - & - & 100 & 44 & 5 & 3 & 10 & - & 5 & 4 & - \\
\hline & homoorientin & - & - & - & - & - & 100 & 42 & 5 & 3 & 12 & - & 5 & 5 & - \\
\hline \multirow{2}{*}{$8-C$} & vitexin & - & - & - & - & - & 100 & 4 & - & - & - & 7 & - & 22 & 3 \\
\hline & orientin & - & - & - & - & - & 100 & 4 & - & - & - & 5 & - & 18 & - \\
\hline
\end{tabular}

${ }^{a}$ Fragments are abbreviated as $-\mathrm{G}$ : loss of one glucose residue, $-\mathrm{F}$ : loss of one flavonoid glucoside molecule, $-\mathrm{A}$ : loss of aglycon portion, $-2 \mathrm{G}$ : loss of two glucose residues, $4-\mathrm{F}$ : loss of one flavonoid glucoside molecule from $\left[2 \mathrm{Mg}(\mathrm{II})(\mathrm{L}-\mathrm{H})_{2}(\mathrm{~L})_{2}\right]^{2+}$.

bThe relative intensity of each fragment ion is an average of 2 to 4 experiments carried out on different days. 

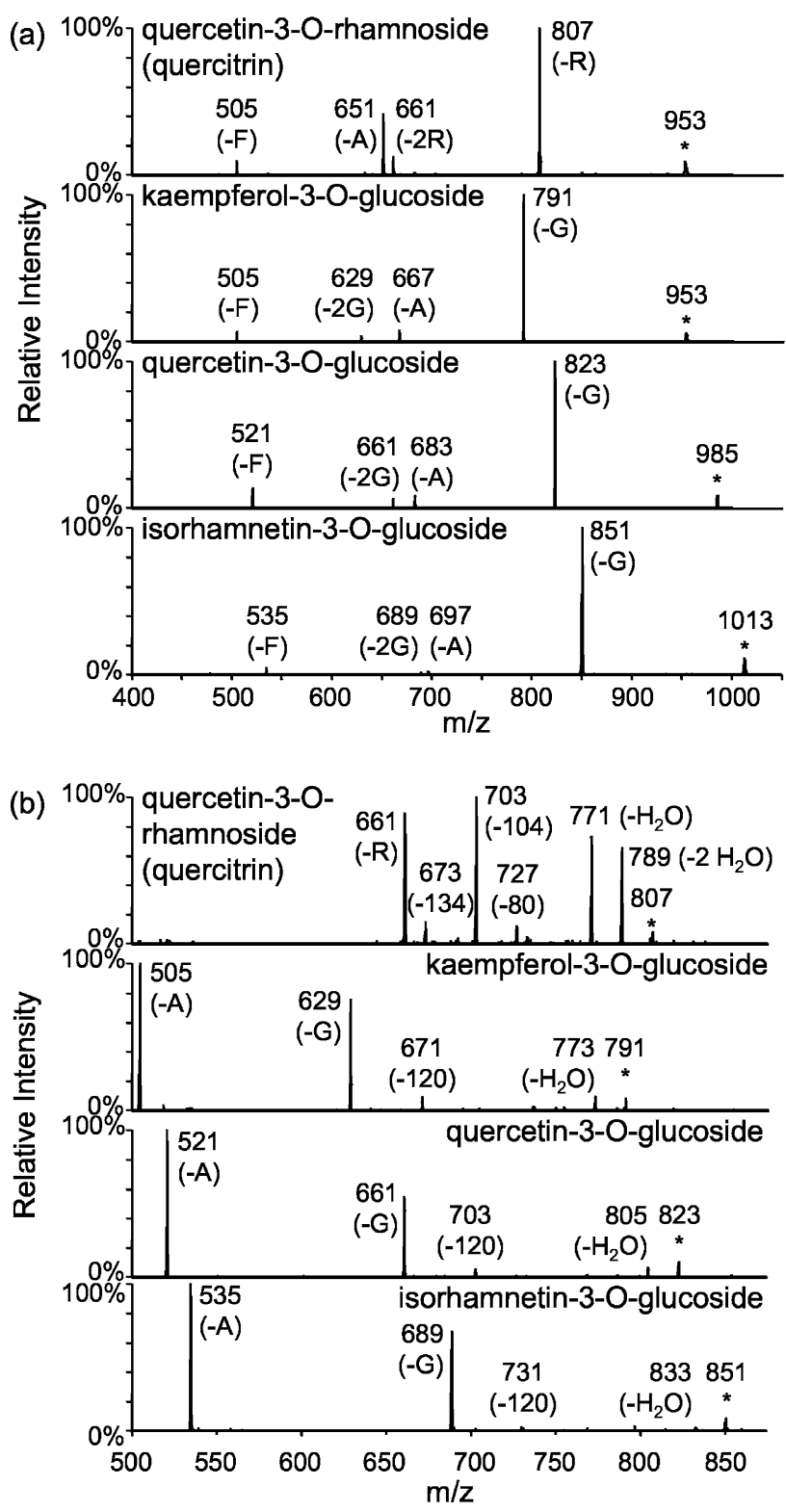

Figure 8. CAD spectra of $[\mathrm{Ni}(\mathrm{II})(\mathrm{L}-\mathrm{H})(\mathrm{L})]^{+}$complexes involving 3-O-glycosyl flavonoids. (a) MS/MS data. (b) $\mathrm{MS}^{3}$ following initial loss of one saccharide moiety. Fragmentation pathways are labeled as: $-\mathrm{G}$ (loss of a glucose residue), $-2 \mathrm{G}$ (loss of two glucose residues), $-\mathrm{R}$ (loss of one rhamnose residue), $-2 \mathrm{R}$ (loss of two rhamnose residues), $-\mathrm{A}$ (loss of aglycon portion), $-\mathrm{F}$ (loss of one flavonoid glycoside molecule).

ison of a flavonoid rhamnoside to the flavonoid glucosides demonstrated that saccharide identity also has a strong effect on the fragmentation of the metal complexes.

\section{Acknowledgments}

This material is based upon work supported under a National Science Foundation Graduate Research Fellowship to BDD. This work was also supported by the National Institutes of Health (NIH RO1 GM63512), the Texas Advanced Research Program (003658-0359), and the Welch Foundation (F-1155).

\section{References}

1. Ross, J. A.; Kasum, C. M. Dietary Flavonoids: Bioavailability, Metabolic Effects, and Safety. Annu. Rev. Nutri. 2002, 22, 19-34.

2. Hertog, M. G. L.; Feskens, E. J. M.; Hollman, P. C. H.; Katan, M. B.; Kromhout, D. Dietary Antioxidant Flavonoids and Risk of Coronary Heart Disease: The Zutphen Elderly Study. Lancet 1993, 342, 1007-1011.

3. Bravo, L. Polyphenols: Chemistry, Dietary Sources, Metabolism, and Nutritional Significance. Nutri. Rev. 1998, 56, 317333.

4. Harborne, J. B. The Flavonoids: Advances in Research Since 1986, 1st ed.; Chapman and Hall: London and New York, 1994, p 377.

5. Cuyckens, F.; Claeys, M. Mass Spectrometry in the Structural Analysis of Flavonoids. J. Mass Spectrom. 2004, 39, 1-15.

6. Stobiecki, M. Application of Mass Spectrometry for Identification and Structural Studies of Flavonoid Glycosides. Phytochemistry 2000, 54, 237-256.

7. Wolfender, J. L.; Maillard, M.; Marston, A.; Hostettmann, K. Mass Spectrometry of Underivatized Naturally Occurring Glycosides. Phytochem. Anal. 1992, 3, 193-214.

8. Schels, H.; Zinsmeister, H. D.; Pfleger, K. Mass Spectrometry of Silylated Flavonol O-Glycosides. Phytochemistry 1977, 16, 1019-1023.

9. Schels, H.; Zinsmeister, H. D.; Pfleger, K. Mass Spectrometry of Silylated Flavone and Flavanone Glycosides. Phytochemistry 1978, 17, 523-526.

10. Mabry, T. J.; Ulubulen, A. Flavonoids and Related Plant Phenolics. In Biochemical Applications of Mass Spectrometry: First Supplementary Volume, Waller, G. R.; Dermer, O. C., Eds.; Wiley: New York, NY, 1980; pp 1131-1158.

11. Stobiecki, M.; Olechnowicz-Stepien, W.; RzadkowskaBodalska, H.; Cisowski, W.; Budko, E. Identification of Flavonoid Glycosides Isolated from Plants by Fast Atom Bombardment Mass Spectrometry and Gas Chromatography/Mass Spectrometry. Biomed. Environ. Mass Spectrom. 1988, 15, 589-594.

12. Borges, C.; Martinho, P.; Martins, A.; Rauter, A. P.; Ferreira, M. A. A. Structural Characterization of Flavonoids and Flavonoid-O-Glycosides Extracted from Genista tenera by FastAtom Bombardment Tandem Mass Spectrometry. Rapid Commun. Mass Spectrom. 2001, 15, 1760-1767.

13. Ma, Y. L.; Li, Q. M.; Van den Heuvel, H.; Claeys, M. Characterization of Flavone and Flavonol Aglycones by CollisionInduced Dissociation Tandem Mass Spectrometry. Rapid Commun. Mass Spectrom. 1997, 11, 1357-1364.

14. Ma, Y.L.; Vedernikova, I.; Van den Heuvel, H.; Claeys, M. Internal Glucose Residue Loss in Protonated O-Diglycosyl Flavonoids Upon Low-Energy Collision-Induced Dissociation. J. Am. Soc. Mass Spectrom. 2000, 11, 136-144.

15. Ma, Y. L.; Van den Heuvel, H.; Claeys, M. Characterization of 3-Methoxyflavones Using Fast-Atom Bombardment and Collision-Induced Dissociation Tandem Mass Spectrometry. Rapid Commun. Mass Spectrom. 1999, 13, 1932-1942.

16. Cuyckens, F.; Ma, Y. L.; Pocsfalvi, G.; Claeys, M. Tandem Mass Spectral Strategies for the Structural Characterization of Flavonoid Glycosides. Analusis 2000, 28, 888-895.

17. Li, Q. M.; Van den Heuvel, H.; Dillen, L.; Claeys, M. Differentiation of 6-C- and 8-C-Glycosidic Flavonoids by Positive Ion Fast Atom Bombardment and Tandem Mass Spectrometry. Biol. Mass Spectrom. 1992, 21, 213-221.

18. Ma, Y. L.; Cuyckens, F.; Van den Heuvel, H.; Claeys, M. Mass Spectrometric Methods for the Characterization and Differentiation of Isomeric O-Diglycosyl Flavonoids. Phytochem. Anal. 2001, 12, 159-165. 
19. Cuyckens, F.; Shahat, A. A.; Pieters, L.; Claeys, M. Direct Stereochemical Assignment of Hexose and Pentose Residues in Flavonoid O-Glycosides by Fast Atom Bombardment and Electrospray Ionization Mass Spectrometry. J. Mass Spectrom. 2002, 37, 1272-1279.

20. Cuyckens, F.; Rozenberg, R.; de Hoffmann, E.; Claeys, M. Structure Characterization of Flavonoid O-Diglycosides by Positive and Negative Nano-Electrospray Ionization Ion Trap Mass Spectrometry. J. Mass Spectrom. 2001, 36, 1203-1210.

21. Cuyckens, F.; Claeys, M. Optimization of a Liquid Chromatography Method Based on Simultaneous Electrospray Ionization Mass Spectrometric and Ultraviolet Photodiode Array Detection for Analysis of Flavonoid Glycosides. Rapid Commun. Mass Spectrom. 2002, 16, 2341-2348.

22. Fabre, N.; Rustan, I.; de Hoffmann, E.; Quetin-Leclercq, J. Determination of Flavone, Flavonol, and Flavanone Aglycones by Negative Ion Liquid Chromatography Electrospray Ion Trap Mass Spectrometry. J. Am. Soc. Mass Spectrom. 2001, 12, 707-715.

23. Hughes, R. J.; Croley, T. R.; Metcalfe, C. D.; March, R. E. A Tandem Mass Spectrometric Study of Selected Characteristic Flavonoids. Int. J. Mass Spectrom. 2001, 210/211, 371-385.

24. Hvattum, E.; Ekeberg, D. Study of the Collision-Induced Radical Cleavage of Flavonoid Glycosides Using Negative Electrospray Ionization Tandem Quadrupole Mass Spectrometry. J. Mass Spectrom. 2003, 38, 43-49.

25. Justesen, U. Collision-Induced Fragmentation of Deprotonated Methoxylated Flavonoids, Obtained by Electrospray Ionization Mass Spectrometry. J. Mass Spectrom. 2001, 36, 169-178.

26. Prasain, J. K.; Patel, R.; Kirk, M.; Wilson, L.; Botting, N.; Darley-Usmar, V. M.; Barnes, S. Mass Spectrometric Methods for the Analysis of Chlorinated and Nitrated Isoflavonoids: A Novel Class of Biological Metabolites. J. Mass Spectrom. 2003, $38,764-771$.

27. Kuhn, F.; Oehme, M.; Romero, F.; Abou-Mansour, E.; Tabacchi, R. Differentiation of Isomeric Flavone/Isoflavone Aglycones by $\mathrm{MS}^{2}$ Ion Trap Mass Spectrometry and a Double Neutral Loss of CO. Rapid Commun. Mass Spectrom. 2003, 17, 1941-1949.

28. Wolfender, J. L.; Waridel, P.; Ndjoko, K.; Hobby, K. R.; Major, H. J.; Hostettmann, K. Evaluation of Q-TOF-MS/MS and Multiple Stage IT-MS ${ }^{\mathrm{n}}$ for the Dereplication of Flavonoids and Related Compounds in Crude Plant Extracts. Analusis 2000, 28, 895-906.

29. Waridel, P.; Wolfender, J. L.; Ndjoko, K.; Hobby, K. R.; Major, H. J.; Hostettmann, K. Evaluation of Quadrupole Time-ofFlight Tandem Mass Spectrometry and Ion-Trap MultipleStage Mass Spectrometry for the Differentiation of C-Glycosidic Flavonoid Isomers. J. Chromatogr. A 2001, 926, 29-41.

30. Rauha, J. P.; Vuorela, H.; Kostiainen, R. Effect of Eluent on the Ionization Efficiency of Flavonoids by Ion Spray, Atmospheric Pressure Chemical Ionization, and Atmospheric Pressure Photoionization Mass Spectrometry. J. Mass Spectrom. 2001, 36, $1269-1280$.

31. de Rijke, E.; Zappey, H.; Ariese, F.; Gooijer, C.; Brinkman, U. A. T. Liquid Chromatography with Atmospheric Pressure Chemical Ionization and Electrospray Ionization Mass Spectrometry of Flavonoids with Triple-Quadrupole and Ion-Trap Instruments. J. Chromatogr. A 2003, 984, 45-58.

32. Keki, S.; Deak, G.; Zsuga, M. Fragmentation Study of Rutin, a Naturally Occurring Flavone Glycoside Cationized with Different Alkali Metal Ions, Using Post-Source Decay MatrixAssisted Laser Desorption/Ionization Mass Spectrometry. J. Mass Spectrom. 2001, 36, 1312-1316.
33. Frison-Norrie, S.; Sporns, P. Identification and Quantification of Flavonol Glycosides in Almond Seedcoats Using MALDITOF MS. J. Agri. Food Chem. 2002, 50, 2782-2787.

34. Franski, R.; Bednarek, P.; Wojtaszek, P.; Stobiecki, M. Identification of Flavonoid Diglycosides in Yellow Lupin (Lupinus luteus L.) with Mass Spectrometric Techniques. J. Mass Spectrom. 1999, 34, 486-495.

35. Justesen, U. Negative Atmospheric Pressure Chemical Ionization Low-Energy Collision Activation Mass Spectrometry for the Characterization of Flavonoids in Extracts of Fresh Herbs. J. Chromatogr. A 2000, 902, 369-379.

36. Hvattum, E. Determination of Phenolic Compounds in Rose Hip (Rosa canina) Using Liquid Chromatography Coupled to Electrospray Ionisation Tandem Mass Spectrometry and Diode-Array Detection. Rapid Commun. Mass Spectrom. 2002, 16, 655-662.

37. Maillard, M. N.; Giampaoli, P.; Cuvelier, M. E. Atmospheric Pressure Chemical Ionisation (APcI) Liquid ChromatographyMass Spectrometry: Characterisation of Natural Antioxidants. Talanta 1996, 43, 339-347.

38. Becchi, M.; Fraisse, D. Fast Atom Bombardment and Fast Atom Bombardment Collision Activated Dissociation/MassAnalyzed Ion Kinetic Energy Analysis of C-Glycosidic Flavonoids. Biomed. Environ. Mass Spectrom. 1989, 18, 122-130.

39. Raffaelli, A.; Moneti, G.; Mercati, V.; Toja, E. Mass Spectrometric Characterization of Flavonoids in Extracts from Passiflora incarnata. J. Chromatogr. A 1997, 777, 223-231.

40. Pietta, P.; Facino, R. M.; Carini, M.; Mauri, P. Thermospray Liquid Chromatography-Mass Spectrometry of Flavonol Glycosides from Medicinal Plants. J. Chromatogr. A 1994, 661, 121-126.

41. Zhang, J.; Satterfield, M. B.; Brodbelt, J. S.; Britz, S. J.; Clevidence, B.; Novotny, J. A. Structural Characterization and Detection of Kale Flavonoids by Electrospray Ionization Mass Spectrometry. Anal. Chem. 2003, 75, 6401-6407.

42. Boue, S. M.; Carter-Wientjes, C. H.; Shih, B. Y.; Cleveland, T. E. Identification of Flavone Aglycones and Glycosides in Soybean Pods by Liquid Chromatography-Tandem Mass Spectrometry. J. Chromatogr. A 2003, 991, 61-68.

43. Sanchez-Rabaneda, F.; Jauregui, O.; Lamuela-Raventos, R. M.; Bastida, J.; Viladomat, F.; Codina, C. Identification of Phenolic Compounds in Artichoke Waste by High-Performance Liquid Chromatography-Tandem Mass Spectrometry. J. Chromatogr. A 2003, 1008, 57-72.

44. Sanchez-Rabaneda, F.; Jauregui, O.; Casals, I.; Andres-Lacueva, C.; Izquierdo-Pulido, M.; Lamuela-Raventos, R. M. Liquid Chromatographic/Electrospray Ionization Tandem Mass Spectrometric Study of the Phenolic Composition of Cocoa (Theobroma cacao). J. Mass Spectrom. 2003, 38, 35-42.

45. Llorach, R.; Gil-Izquierdo, A.; Ferreres, F.; Tomas-Barberan, F. A. HPLC-DAD-MS/MS ESI Characterization of Unusual Highly Glycosylated Acylated Flavonoids from Cauliflower (Brassica oleracea L. var. botrytis) Agroindustrial Byproducts. J. Agri. Food Chem. 2003, 51, 3895-3899.

46. Edenharder, R.; Keller, G.; Platt, K. L.; Unger, K. K. Isolation and Characterization of Structurally Novel Antimutagenic Flavonoids from Spinach (Spinacia oleracea). J. Agri. Food Chem. 2001, 49, 2767-2773.

47. Satterfield, M.; Black, D. M.; Brodbelt, J. S. Detection of the Isoflavone Aglycones Genistein and Daidzein in Urine Using Solid-Phase Microextraction-High-Performance Liquid Chromatography-Electrospray Ionization Mass Spectrometry. J. Chromatogr. B 2001, 759, 33-41.

48. Nielsen, S. E.; Freese, R.; Cornett, C.; Dragsted, L. O. Identification and Quantification of Flavonoids in Human Urine Samples by Column-Switching Liquid Chromatography Cou- 
pled to Atmospheric Pressure Chemical Ionization Mass Spectrometry. Anal. Chem. 2000, 72, 1503-1509.

49. Mauri, P. L.; Iemoli, L.; Gardana, C.; Riso, P.; Simonetti, P.; Porrini, M.; Pietta, P. G. Liquid Chromatography/Electrospray Ionization Mass Spectrometric Characterization of Flavonol Glycosides in Tomato Extracts and Human Plasma. Rapid Commun. Mass Spectrom. 1999, 13, 924-931.

50. Zhang, J.; Brodbelt, J. S. Structural Characterization and Isomer Differentiation of Chalcones by Electrospray Ionization Tandem Mass Spectrometry. J. Mass Spectrom. 2003, 38, 555572.

51. Satterfield, M.; Brodbelt, J. S. Structural Characterization of Flavonoid Glycosides by Collisionally Activated Dissociation of Metal Complexes. J. Am. Soc. Mass Spectrom. 2001, 12, 537-549.

52. Pikulski, M.; Brodbelt, J. S. Differentiation of Flavonoid Glycoside Isomers by Using Metal Complexation and Electrospray Ionization Mass Spectrometry. J. Am. Soc. Mass Spectrom. 2003, 14, 1437-1453.

53. Zhang, J.; Brodbelt, J. Gas-Phase Hydrogen/Deuterium Exchange and Conformations of Deprotonated Flavonoids and Gas-Phase Acidities of Flavonoids. J. Am. Chem. Soc. 2004, 126, 5906-5919.

54. Bakhtiar, A.; Gleye, J.; Moulis, C.; Fouraste, I. Desorption Chemical Ionization Mass Spectrometry of C-Glycosylflavones. Phytochem. Anal. 1994, 5, 86-89.

55. Alvarez, E. J.; Vartanian, V. H.; Brodbelt, J. S. Metal Complexation Reactions of Quinolone Antibiotics in a Quadrupole Ion Trap. Anal. Chem. 1997, 69, 1147-1155.

56. Alvarez, E. J.; Brodbelt, J. S. Evaluation of Metal Complexation as an Alternative to Protonation for Electrospray Ionization of Pharmaceutical Compounds. J. Am. Soc. Mass Spectrom. 1998, 9, 463-472.

57. Shen, J.; Brodbelt, J. S. Post-Column Metal Complexation of Quinolone Antibiotics in a Quadrupole Ion Trap. Rapid Commun. Mass Spectrom. 1999, 13, 1381-1389.

58. Smith, G.; Leary, J. A. Differentiation of Stereochemistry of Glycosidic Bond Configuration: Tandem Mass Spectrometry of Diastereomeric Cobalt-Glucosyl-Glucose Disaccharide Complexes. J. Am. Soc. Mass Spectrom. 1996, 7, 953-957.

59. Gaucher, S. P.; Leary, J. A. Stereochemical Differentiation of Mannose, Glucose, Galactose, and Talose Using Zinc(II) Diethylenetriamine and ESI-Ion Trap Mass Spectrometry. Anal. Chem. 1998, 70, 3009-3014.

60. Gaucher, S. P.; Leary, J. A. Determining Anomericity of the Glycosidic Bond in Zn(II)-Diethylenetriamine-Disaccharide Complexes Using $\mathrm{MS}^{\mathrm{n}}$ in a Quadrupole Ion Trap. J. Am. Soc. Mass Spectrom. 1999, 10, 269-272.

61. Gaucher, S. P.; Leary, J. A. Influence of Metal Ion and Coordination Geometry on the Gas Phase Dissociation and Stereochemical Differentiation of N-Glycosides. Int. J. Mass Spectrom. 2000, 197, 139-148.

62. Konig, S.; Leary, J. A. Evidence for Linkage Position Determination in Cobalt Coordinated Pentasaccharides Using Ion Trap Mass Spectrometry. J. Am. Soc. Mass Spectrom. 1998, 9, $1125-1134$.
63. Desaire, H.; Leary, J. A. Utilization of $\mathrm{MS}^{3}$ Spectra for the Multicomponent Quantification of Diastereomeric N-Acetylhexosamines. J. Am. Soc. Mass Spectrom. 2000, 11, 1086-1094.

64. Desaire, H.; Beyer, M. K.; Leary, J. A. Molecular Orbital Considerations in Probing the Stereoselective Dissociations of Cobalt-Coordinated Hexosamine Monosaccharides. J. Am. Soc. Mass Spectrom. 2001, 12, 517-527.

65. Desaire, H.; Leary, J. A. The Effects of Coordination Number and Ligand Size on the Gas Phase Dissociation and Stereochemical Differentiation of Cobalt-Coordinated Monosaccharides. Int. J. Mass Spectrom. 2001, 209, 171-184.

66. Basso, E.; Chilin, A.; Guiotto, A.; Traldi, P. Electrospray Mass Spectrometry in the Differentiation of Some Isomeric Trimethylfurocoumarins. Rapid Commun. Mass Spectrom. 2003, 17, 2781-2787.

67. Ho, Y. P.; Huang, P. C.; Deng, K. H. Metal Ion Complexes in the Structural Analysis of Phospholipids by Electrospray Ionization Tandem Mass Spectrometry. Rapid Commun. Mass Spectrom. 2003, 17, 114-121.

68. Asam, M. R.; Glish, G. L. Tandem Mass Spectrometry of Alkali Cationized Polysaccharides in a Quadrupole Ion Trap. J. Am. Soc. Mass Spectrom. 1997, 8, 987-995.

69. Seymour, J. L.; Turecek, F. Distinction and Quantitation of Leucine-Isoleucine Isomers and Lysine-Glutamine Isobars by Electrospray Ionization Tandem Mass Spectrometry $\left(\mathrm{MS}^{\mathrm{n}}, \mathrm{n}=\right.$ 2,3) of Copper(II)-Diimine Complexes. J. Mass Spectrom. 2000, $35,566-571$.

70. Vaisar, T.; Gatlin, C. L.; Rao, R. D.; Seymour, J. L.; Turecek, F. Sequence Information, Distinction, and Quantitation of CTerminal Leucine and Isoleucine in Ternary Complexes of Tripeptides with $\mathrm{Cu}(\mathrm{II})$ and 2,2'-Bipyridine. J. Mass Spectrom. 2001, 36, 306-316.

71. Carlesso, V.; Fournier, F.; Tabet, J. C. Stereochemical Differentiation of Four Monosaccharides Using Transition Metal Complexes by Electrospray Ionization/Ion-Trap Mass Spectrometry. Eur. J. Mass Spectrom. 2000, 6, 421-428.

72. Satterfield, M.; Brodbelt, J. S. Enhanced Detection of Flavonoids by Metal Complexation and Electrospray Ionization Mass Spectrometry. Anal. Chem. 2000, 72, 5898-5906.

73. Moridani, M. Y.; Pourahmad, J.; Bui, H.; Siraki, A.; O'Brien, P. J. Dietary Flavonoid Iron Complexes as Cytoprotective Superoxide Radical Sscavengers. Free Rad. Biol. Med. 2003, 34, 243-253.

74. Weber, G. HPLC with Electrochemical Detection of Metal Flavonoid Complexes Isolated from Food. Chromatographia 1988, 26, 133-138.

75. de Souza, R. F. V.; Sussuchi, E. M.; De Giovani, W. F. Synthesis, Electrochemical, Spectral, and Antioxidant Properties of Complexes of Flavonoids with Metal Ions. Synth. React. Inorg. Metal-Org. Chem. 2003, 33, 1125-1144.

76. Soczynska-Kordala, M.; Bakowska, A.; Oszmianski, J.; Gabrielska, J. Metal Ion-Flavonoid Associations in Bilayer Phospholipid Membranes. Cell. Mol. Biol. Lett. 2001, 6, 277-281.

77. Fernandez, M. T.; Mira, M. L.; Florencio, M. H.; Jennings, K. R. Iron and Copper Chelation by Flavonoids: An Electrospray Mass Spectrometry Study. J. Inorg. Biochem. 2002, 92, 105-111. 